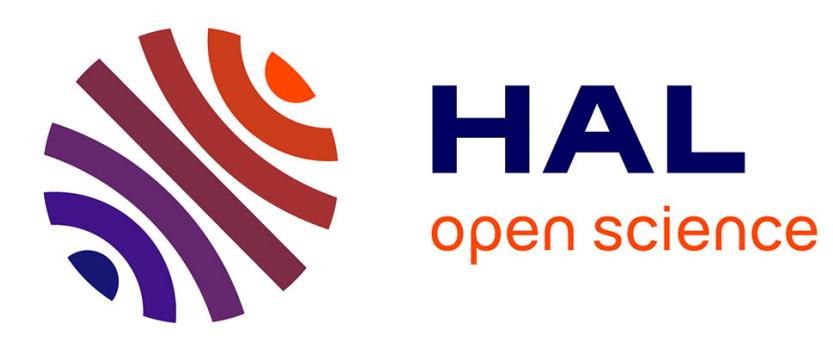

\title{
Misfit accommodation and dislocations in heteroepitaxial semiconductor layers: II-VI compounds on GaAs
}

G. Patriarche, Jérôme Rivière, J. Castaing

\section{- To cite this version:}

G. Patriarche, Jérôme Rivière, J. Castaing. Misfit accommodation and dislocations in heteroepitaxial semiconductor layers: II-VI compounds on GaAs. Journal de Physique III, 1993, 3 (6), pp.1189-1199. 10.1051/jp3:1993193 . jpa-00248992

\section{HAL Id: jpa-00248992 https://hal.science/jpa-00248992}

Submitted on 1 Jan 1993

HAL is a multi-disciplinary open access archive for the deposit and dissemination of scientific research documents, whether they are published or not. The documents may come from teaching and research institutions in France or abroad, or from public or private research centers.
L'archive ouverte pluridisciplinaire HAL, est destinée au dépôt et à la diffusion de documents scientifiques de niveau recherche, publiés ou non, émanant des établissements d'enseignement et de recherche français ou étrangers, des laboratoires publics ou privés. 
Classification

Physics Abstracts

$68.55 \mathrm{C}-68.35 \mathrm{D}-61.70 \mathrm{~J}$

\title{
Misfit accommodation and dislocations in heteroepitaxial semiconductor layers : II-VI compounds on GaAs
}

\author{
G. Patriarche, J. P. Rivière and J. Castaing \\ Laboratoire Physique des Matériaux, CNRS Bellevue, 92195 Meudon Cedex, France
}

(Received 17 September 1992, accepted 17 March 1993)

\begin{abstract}
Résumé. - Nous proposons un mécanisme de germination et de développement des dislocations permettant de compenser l'écart de paramètres d'une couche épitaxiée sur un substrat, par exemple dans notre cas, un composé II-VI sur GaAs. On porte une attention particulière aux dislocations résiduelles dans la couche dont on cherche à minimiser la densité.
\end{abstract}

\begin{abstract}
We suggest a model for the nucleation and expansion of dislocations which accommodate the parameter misfit of an epitaxial layer on a substrate, applied, in this work, to a II-VI compound on GaAs. We examine in particular the dislocations threading through the layer, which must be kept as low as possible in density.
\end{abstract}

\section{Introduction.}

A large number of investigations have been performed on the properties of III-V semiconductor layers in epitaxy on a substrate. A system which has received a great deal of attention in GaAs on Si $[1,2]$ expecting to take advantage of the performance of silicon single crystals, in spite of the large parameter misfit $(\Delta a / a=4 \%)$.

The II-VI semiconductors are attractive because they can be used in opto-electronic devices, for wavelengths which do not correspond to any III-V compounds. For instance, $(\mathrm{CdHg}) \mathrm{Te}$ permits infra-red detection, for wavelengths up to $10 \mu \mathrm{m}$ by adjusting the mercury concentration [3].

Attempts have been made to prepare good quality $(\mathrm{CdHg}) \mathrm{Te}$ epitaxial layers by MOCVD. In order to spread the lattice mismatch between the layers and the GaAs substrates, intermediate layers are grown, viz. ZnTe on GaAs $(\Delta a / a=8 \%)$ followed by alternative CdTe and $\mathrm{HgTe}$ growth aiming at achieving a $\mathrm{Cd} / \mathrm{Hg}$ ratio by interdiffusion. The two compounds have almost the same parameter (Tab. I) which in $6 \%$ larger than the one of ZnTe [4].

We have examined the microstructure of such epitaxial layers, mainly using transmission electron microscopy (TEM). A prominent feature is the presence of large dislocation densities from the interfaces to the surface of the layers. In this paper, we present a model which allows us to describe the formation of dislocations which accommodate the lattice mismatch and to explain the presence of excess dislocations in the epitaxial layers. These considerations may 
Table I. - Principal parameters of semiconductor compounds involved in the present study.

\begin{tabular}{|c|c|c|c|c|c|}
\hline & GaAs & $\mathrm{ZnTe}$ & $\mathrm{CdTe}$ & $\mathrm{HgTe}$ & References \\
\hline $\begin{array}{c}a(\mathrm{~nm}) \\
\text { lattice } \\
\text { parameters }\end{array}$ & 0.565 & 0.6104 & 0.6481 & 0.6461 & {$[12]$} \\
\hline$\frac{\Delta a}{a}=\frac{2\left(a_{1}-a_{2}\right)}{a_{1}+a_{2}}$ & \multicolumn{5}{|c|}{$\leftarrow 7.7 \% \rightarrow \quad \leftarrow 6 \% \rightarrow \quad \leftarrow 0.3 \% \rightarrow$} \\
\hline $\begin{array}{c}\text { elastic } \\
\text { constants } \\
\left(10^{10} \mathrm{~Pa}\right) \\
\mathrm{C}_{11} \\
\mathrm{C}_{12} \\
\mathrm{C}_{44}\end{array}$ & $\begin{array}{r}11.92 \\
5.94 \\
5.38\end{array}$ & $\begin{array}{l}6.99 \\
3.99 \\
3.06\end{array}$ & $\begin{array}{l}5.25 \\
3.61 \\
1.95\end{array}$ & $\begin{array}{l}5.37 \\
3.74 \\
2.01\end{array}$ & [13] \\
\hline $\begin{array}{l}\text { thermal } \\
\text { expansion } \\
10^{-6} \mathrm{~K}^{-1}\end{array}$ & 6 & 8.4 & 4.9 & 5.1 & {$[12],[13]$} \\
\hline $\begin{array}{l}\text { slip system } \\
\text { dissociation }\end{array}$ & \multicolumn{5}{|c|}{$\begin{array}{l}1 / 2\langle 1 \overline{1} 0\rangle\{111\} \\
\rightarrow \quad 1 / 6\langle 2 \overline{1} 1\rangle+1 / 6\langle 1 \overline{2} \overline{1}\rangle\end{array}$} \\
\hline $\begin{array}{c}\text { stacking } \\
\text { fault energy } \\
\mathrm{mJ} \cdot \mathrm{m}^{-2}\end{array}$ & $\begin{array}{l}20 \\
\text { to } \\
50\end{array}$ & 14 & 9 & & {$[12],[14]$} \\
\hline
\end{tabular}

apply to a number of situations where heteroepitaxial semiconductor layers are grown on a perfect substrate with large lattice mismatch.

\section{Experimental conditions.}

We have gathered in table I the main parameters of the materials under investigation. The epitaxial layers are prepared by MOCVD at temperatures of $350-400{ }^{\circ} \mathrm{C}$ [5]. The difference in thermal expansion can create some stress during cooling to room temperature, the layers being grown stress free once the lattice mismatch is relaxed. One calculates from elasticity theory that cooling implies a shear stress of $2.7 \mathrm{MPa}$, which is opposite to misfit stress. Such stress value is too low to induce dislocation motion and multiplication in the II-VI semiconductor layer.

For transmission electron microscopy (TEM), two kinds of foils were prepared. Plan view observations were performed with the foil parallel to the $\{100\} \mathrm{ZnTe} / \mathrm{GaAs}$ interface. The materials are mechanically polished, using a « dimpler » on the GaAs sides, until the interface is reached. Further thinning is obtained by chemical etching until electron transparency. Ion thinning for plane views is avoided because of the important damage induced by this technique in II-VI semiconductors as formerly observed in CdTe [6].

Cross-section observations have also been performed. The surfaces of two ZnTe layers are glued together, with matching crystallographic orientations. Foils are then cut perpendicular to 
the glued interfaces and parallel to $\{110\}$ planes. A dimple is obtained by mechanical polishing, before submitting the foils to ion thinning under low beam intensity to prevent the formation of damage. The variety of materials to be etched does not allow us to use chemical thinning.

TEM images were obtained either in a JEOL $100 \mathrm{C}$ machine or in a JEOL 2000FX operated respectively at $100 \mathrm{kV}$ and $200 \mathrm{kV}$, the second permitting resolution of the double atomic columns along $\langle 110\rangle$ directions.

\section{Different ways of misfit accommodation.}

3.1 ElASTIC DEFORMATION OF EPITAXIAL LAYERS. - The parameter of ZnTe is, almost, $8 \%$ larger than the one of GaAs (Tab. I). ZnTe epitaxial layers are therefore submitted to large compressive stresses; their value is of the order of one tenth of the elastic modulus for an homogeneously strained layer, assuming linear elasticity. We take the axis 1 and 2 in the interface ; we write $\varepsilon_{1}=\varepsilon_{2}=-0.08$. The deformation along the axis 3 perpendicular to the interface can be written : $\varepsilon_{3}=-2 C_{12} \varepsilon_{1} / C_{11}=0.09$. For the purpose of describing dislocation motion in the epitaxial layers, we will assume that it is submitted to a tensile stress $\sigma_{3}$ parallel to the axis 3 . the other stresses being isostatic $\sigma_{1}=\sigma_{2}=-\sigma_{3}$, without influence on the motion of dislocation.

3.2 Dislocations In ZnTe/GaAs INTERfaces. - Dislocations in the interface are the most efficient way to relax the strain accumulated in the layer. If the lattice parameters are $a_{1}$ and $a_{2}$ for GaAs and ZnTe, respectively, the average distance $\delta_{0}$ between misfit dislocations corresponds to the shortest distance permitting the correspondence between atomic planes of epilayer and substrate. One finds : $\delta_{0}=d_{2} \frac{a_{1}}{\Delta a}$ where $\Delta a / a_{1}$ is the misfit and $d_{2}$ is the repeat distance in the interface. For every distance $\delta_{0}$, there is a missing plane in ZnTe compared to $\mathrm{GaAs}$, i.e. a dislocation along a line $U$ ending the extra-plane with a Burgers vectors $\mathbf{b}$, such that its edge component in the interface plane $\mathbf{b}^{\prime \prime}$ is equal to the lattice repeat distance $\left(d_{2}\right.$ in the earlier formula). Extra half planes and dislocations can be seen by a careful examination of figure 1 obtained by high resolution TEM. Since the observation was made along $\langle 110\rangle$, the average distance between dislocations, which is expected (Tab. II), is given by

$$
\delta_{0}=\frac{a_{2}}{\sqrt{2}} \frac{a_{1}}{\Delta a}=5.4 \mathrm{~nm} .
$$

The experimental value is in good agreement.

The full relaxation of the $\mathrm{ZnTe}$ layer requires an other set of dislocations, which relieves the misfit in the perpendicular direction.

The dislocations observed in figure 1 belong to those which can be predicted from a crystallographic approach; their characteristics are given in table II for a (001) interface plane. Type $\langle A\rangle$ dislocations have b parallel to the interface (Lomer dislocations), corresponding to the dominant observations (Fig. 1). These Lomer dislocations are sessile and therefore cannot be introduced directly by dislocation multiplication and slip. They are formed by reaction of mobile (B) dislocations; this is suggested by TEM observations of threading dislocations (Fig. 2) which represent the ending of the interface dislocations, as sketched in figure 3 for the beginning of their development. A and B are the emergences with an extra half plane in GaAs and $\mathrm{ZnTe}$ below the dislocation line (Fig. 3). Strain relief is achieved in the upper part above the dislocation line (Figs. 3 and $4 \mathrm{~b}$ ). 


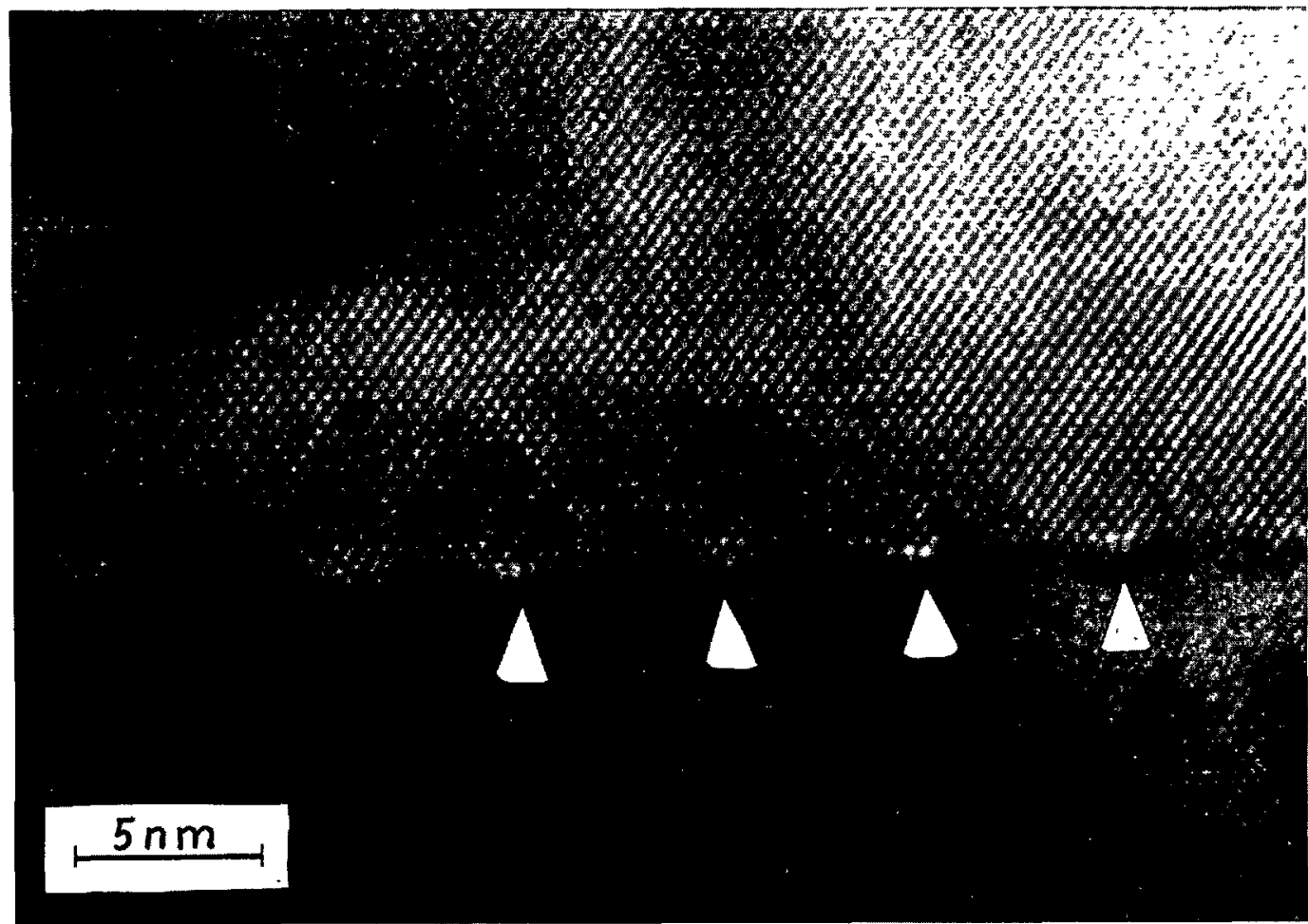

Fig. 1. - High resolution TEM cross section of a $\mathrm{ZnTe} / \mathrm{GaAs}$ interface. The mean spacing between Lomer misfit dislocations (shown by arrows) is about $5.2 \mathrm{~nm}$.

Table II. - Types of dislocations which are able to relieve misfit strains: efficient components $b^{\prime \prime}$ of perfect $b$ and partial $b^{\prime}$ Burgers vectors. They are given together with the corresponding average distance $\delta_{0}$ between misfit dislocations and their Schmid factor under the tensile stress $\sigma_{3}$ for slip in one of the four $\{111\}$ planes.

\begin{tabular}{|c|c|c|c|c|}
\hline & type & $b^{\prime \prime}$ & $\delta_{0}(\mathrm{~nm})$ & $s$ \\
\hline$b=\frac{1}{2}[\overline{1} 10]$ & $\langle\mathrm{A}\rangle$ & $b$ & 5.4 & 0 \\
\hline$b^{\prime}=\frac{1}{6}[1 \overline{2} 1]$ & $\langle B\rangle$ & $0.28 b^{\prime}$ & 0.9 & 0.242 \\
\hline$b=\frac{1}{2}[0 \overline{1} 1]$ & $\langle\mathrm{B}\rangle$ & $0.5 b$ & 2.7 & 0.405 \\
\hline$b^{\prime}=\frac{1}{6}[\overline{1} \overline{1} 2]$ & $\langle\mathrm{B}\rangle$ & $0.57 b^{\prime}$ & 1.8 & 0.47 \\
\hline
\end{tabular}




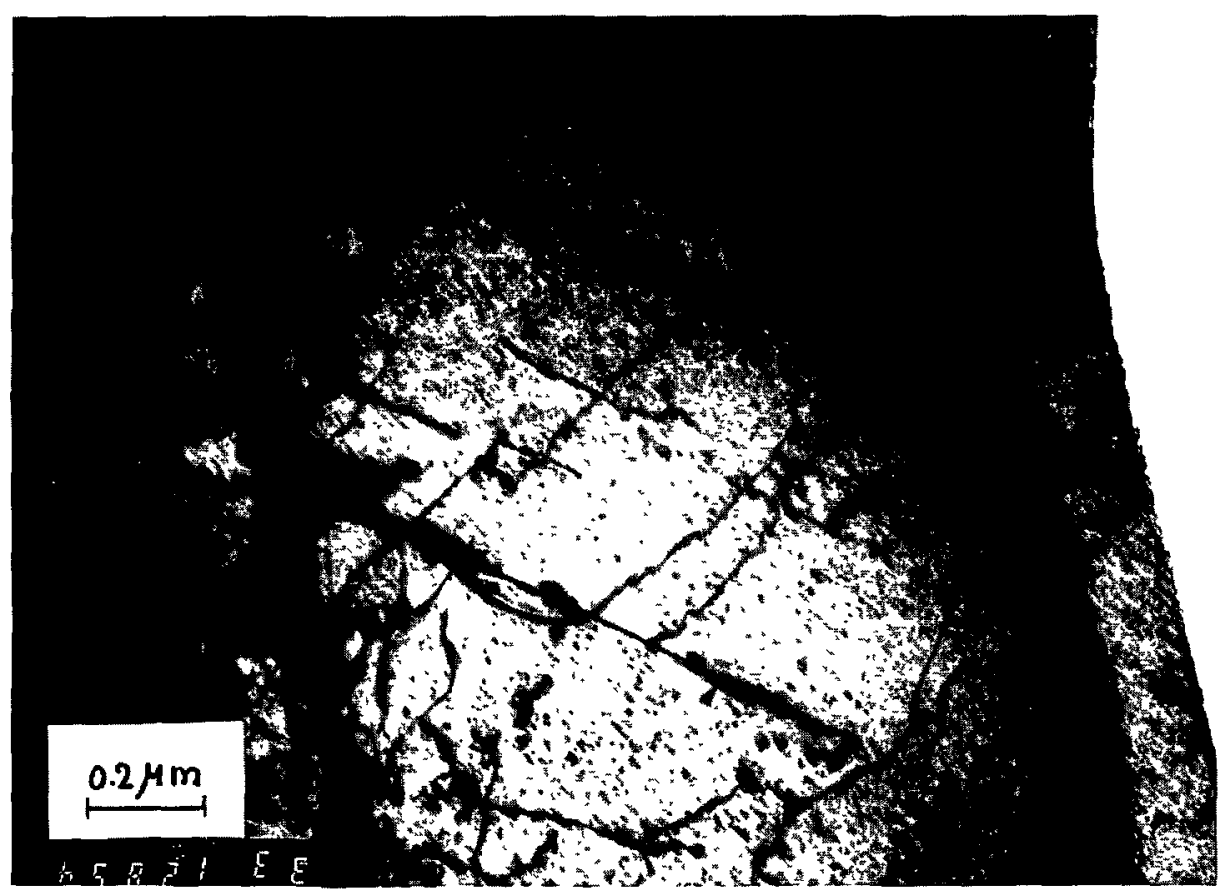

Fig. 2. - Threading dislocations in a $\mathrm{CdTe}(2 \mu \mathrm{m}) / \mathrm{ZnTe}(0.1 \mu \mathrm{m}) / \mathrm{GaAs}\{001\}$ TEM cross section micrograph. The GaAs substrate on the left contains no defect.

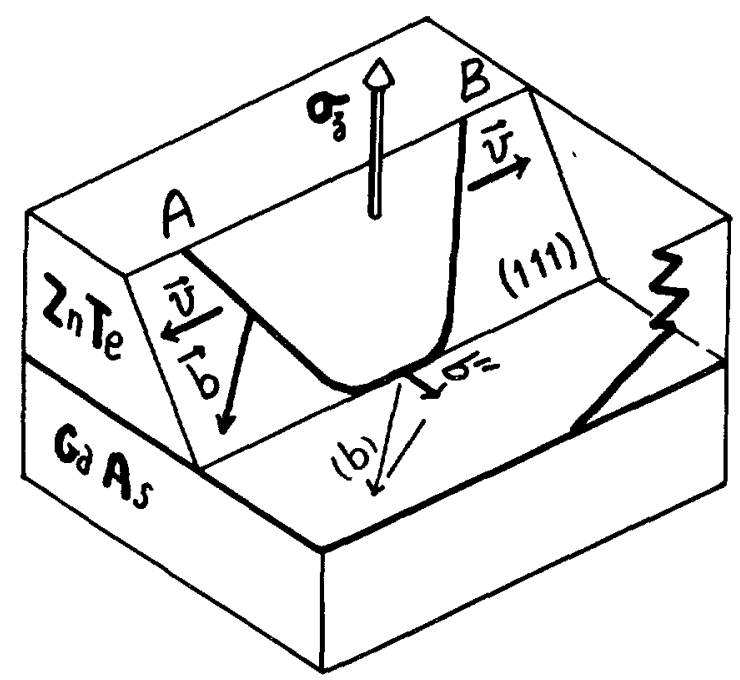

Fig. 3. - Schematic representation of a dislocation threading from $\mathrm{A}$ and $\mathrm{B}$ to the interface, gliding in a $\{111\}$ plane. $b$ and $v$ represent the Burgers vector and the glide direction of dislocations respectively. $b^{\prime \prime}$ is the edge component of the Burgers vector in the interface which relieves the compressive strain between the emergence points $\mathrm{A}$ and $\mathrm{B}$ of the dislocation. 


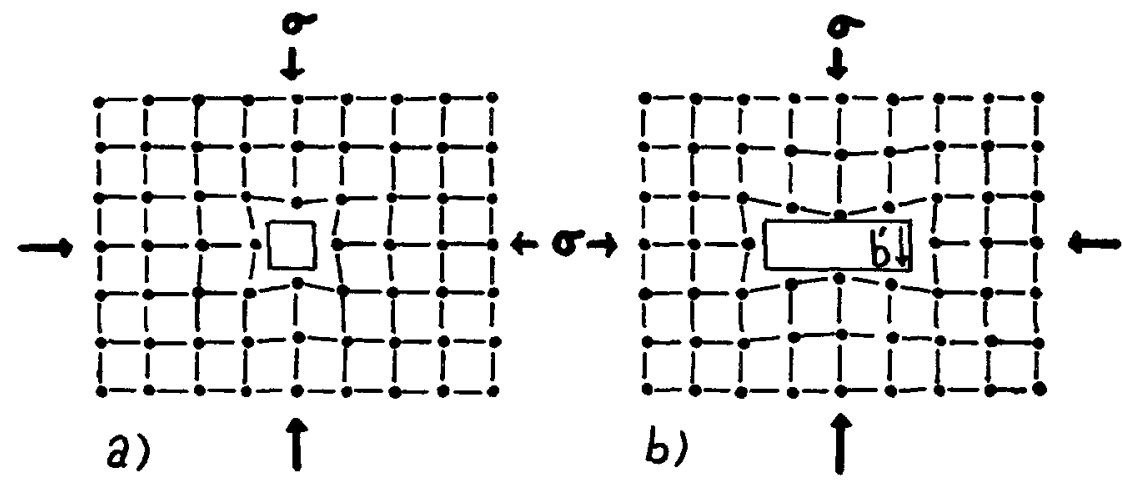

Fig. 4. - Example of packing of vacancies nucleating the dislocation represented in figure 3, during deposition of ZnTe on GaAs. a) First layer on top of the substrate. b) Following layer. $b^{\prime}$, $a$ Burgers vector component, represents $b$ or $b^{\prime \prime}$ for a $\langle\mathrm{A}\rangle$ or $\langle\mathrm{B}\rangle$ dislocation in formation.

A three dimensional dislocation network can relieve the misfit in epitaxial layers ; however, it will be detrimental to electronic properties of the semiconductor.

3.3 ROLE OF POINT DEFECTS. - ZnTe having a lattice parameter greater than GaAs, vacancies can help to relax the epitaxial layer. Their formation is favoured in stressed materials. as well as by the chemical vapor deposition process which deposit atoms from a gaseous phase. Vacancy supersaturation is expected in the growing layer.

In a numerical simulation, Djafari et al. [7] have shown that when CdTe is grown on GaAs, about $10 \%$ of the sites remain vacant. In order to achieve total relief of the misfit, the vacancy concentration must be twice $\Delta a / a$, assuming vacancy and atomic volumes identical ; for CdTe on GaAs, this would give $28 \%$ (Tab. I) well above the value of $10 \%$ found by simulation [7].

For $\mathrm{ZnTe}$, the vacancy concentration would be $16 \%$. There is no evidence that such large amounts of vacancies are present in growing epitaxial layers. However, these defects may partly relieve the misfit at the early stage of growth and play as essential role in the nucleation of dislocations.

Indeed, let us consider an isolated vacancy in the first layer (Fig. 4a). A configuration such as the one of figure $4 \mathrm{~b}$ is very likely for the second layer, because it is the most efficient to relieve the misfit. After several planes, a dislocation of Burgers vector $b$ (Fig. 4b) is created. In this example the missing plane would create a type $\langle A\rangle$ dislocation (Tab. II) which cannot expand under the stress $\sigma_{3}$ and does not bring further misfit relief.

Vacancy clustering can also create type $\langle\mathrm{B}\rangle$ dislocations (Fig. 3) and partial dislocations (Tab. II). They are glissile and can move in order to decrease the total energy of the system. The observed $\langle A\rangle$ sessile dislocations (Fig. 1) are certainly due to a combination of $\langle B\rangle$ dislocations gliding in two symmetric $\{111\}$ planes inclined $55^{\circ}$ at the interface.

\section{Critical thickness.}

The first atomic layers of a growing film are strained to match the substrate, with a small fraction of relief due to point defects, which are, most probably, clustered because of their large concentration (see Sect. 3). For a critical thickness, dislocations appear and contribute to strain relief. There are many calculations of the critical thickness in the literature, based on various criteria [9].

An estimate is obtained by writing that the energy $W_{\mathrm{h}}$ of the homogeneously strained film is equal to that of the dislocation network $\left(W_{\mathrm{d}}\right)$ at the critical thickness $h=h_{\mathrm{c}}$. 
For the unit surface, classical results are :

$$
\begin{aligned}
& W_{\mathrm{h}}=2 \mu \frac{1+\nu}{1-\nu} h\left(\frac{\Delta a}{a}\right)^{2} \\
& W_{\mathrm{d}}=\frac{2}{\delta}\left(\frac{\mu b^{2}}{4 \pi} \ln \frac{R}{b}+W_{\mathrm{c}}\right)
\end{aligned}
$$

where $\mu$ is the elastic shear modulus, $\nu$ is the Poisson's ratio, $R$ is the smallest value between the film thickness $h$ and half the average distance $\delta$ between misfit dislocations for thick films, and $W_{\mathrm{c}} \cong 0.25 \mu b^{2}$ is the dislocation core energy. A straightforward calculation gives for ZnTe on GaAs with type $\langle A\rangle$ dislocations :

$$
h_{\mathrm{c}} \approx 0.13 \frac{b}{\Delta a / a}=1.7 \mathrm{~b} \text {. }
$$

For $b=a \sqrt{2}=0.42 \mathrm{~nm}$ we find $h_{\mathrm{c}}=0.7 \mathrm{~nm}$. This corresponds to a few atomic layers.

This result agrees with the one deduced from equation (23) in Ball and Van der Merwe [9] and with an extrapolation of the experimental data of Cibert et al. [10] for CdTe on (CdZn)Te. For $1 \%<\Delta a / a<6 \%$ the experimental $h_{c}$ varies as $(\Delta a / a)^{-115}$ and our calculations give $(\Delta a / a)^{-1}$. In spite of the assumption of linear elasticity for large deformations, the energetic models are adequate for the prediction of critical thicknesses.

The presence of dislocations implies that they can move for the thickness $h_{\mathrm{c}}$, being more likely to glide under the misfit stress $\tau_{\mathrm{c}}=s \sigma_{3}(s=$ schmid factor, Tab. II). At the critical thickness, the work done on a moving dislocation segment nearly perpendicular to the interface, is of the order of $\tau_{c} b h_{c}$ for unit length displacement. The interface dislocations energy is increased by $W_{\mathrm{d}}$.

By writing $\tau_{\mathrm{c}} b h_{\mathrm{c}}=W_{\mathrm{d}}$, one can deduce again :

$$
h_{\mathrm{c}} \sim 0.13 \frac{b}{\Delta a / a}
$$

The critical thickness values deduced from the two approaches are identical. This means that the conditions are gathered to relax the misfit by moving dislocation segments reaching the surface from the interface, point defect clusters (see Sect. 3.3) being good candidates for these dislocation nuclei.

\section{Formation of dislocation networks.}

In the previous sections, we have examined the driving forces and the critical conditions for the presence of dislocations in epitaxial layers. We now describe a few of the steps required to organize the dislocation microstructure formed while the layer is growing.

As soon as a dislocation length $\ell$ is formed, the stress $\sigma$ in the layer is reduced. We can write :

$$
\sigma=\sigma_{0}\left(1-\ell / \ell_{0}\right)
$$

where $\sigma_{0}$ is the stress before the formation of dislocation, and $\ell_{0}$ the ideal length of dislocations per surface unit to accommodate the parameter mismatch i.e. $\ell_{0}=\frac{2}{\delta_{0}}$ The control of the regular dislocation spacing is a direct consequence of the previous equation. If locally the formation of dislocations has been faster than elsewhere, the stress becomes smaller, thus slowing the dislocation motion and giving time to the surrounding ones to reach 
the same density. This explains why the misfit dislocation arrays in the interface are very regular (Fig. 1). We have suggested that interface dislocations are created by extension of segments of the type shown in figure 3 . This implies an array of points where dislocations cuts the surface. This is displayed in figure 5 , where the distances between two points range from $20 \mathrm{~nm}$ to $50 \mathrm{~nm}$, at an early stage of the growth, for a $50 \mathrm{~nm}$ thick layer. By taking that two points correspond to a dislocation segment, one can calculate the average length of an interface dislocation in $\mathrm{ZnTe}$ on GaAs. For a dislocation density $2 \times 10^{11} \mathrm{~cm}^{-2}$ corresponding to a $20 \mathrm{~nm}$ distance, the total length of interface dislocations is about $4 \times 10^{6} \mathrm{~cm} / \mathrm{cm}^{2}$ which is distributed over segments of average length of $0.4 \mu \mathrm{m}$. The high resolution TEM image of figure 1 requires straight dislocations through the foil, a condition easily encountered with segments $0.4 \mu \mathrm{m}$ long or more. In this case (Fig. 5) the nucleus density would be equal to the half dislocation density : $10^{11} \mathrm{~cm}^{-2}$

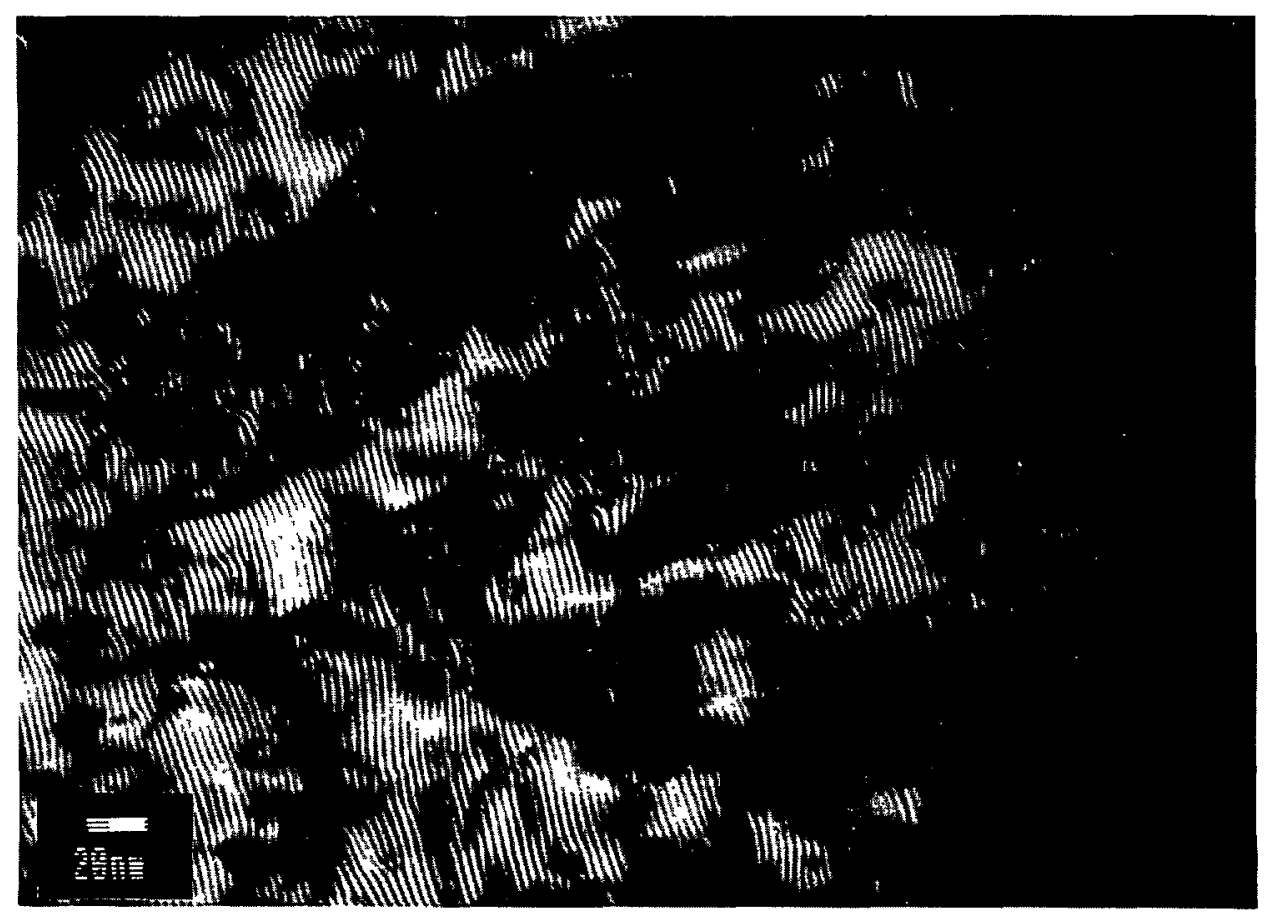

Fig. 5. - TEM plane view of a $50 \mathrm{~nm}$ thick layer of $\mathrm{ZnTe}$ on GaAs with diffraction vector $\langle 220\rangle$ in ZnTe and GaAs. Endings of moiré lines localize the emergences of dislocations (as A or B in Fig. 3). Keep in mind that fluctuations in the direction of moire lines is much larger than the rotation of the layer crystal lattice.

If we assume that a volume of vacancies equal to a unit cell is necessary to create a dislocation nucleus, we can calculate the vacancy concentration in the layer of thickness $h_{\mathrm{c}}$ and $1 \mathrm{~cm}^{2}$ area. With $10^{11} \mathrm{~cm}^{2}$ nucleus, the vacancy concentration can be calculated as $4 \times 10^{-4}$ This value is much larger that the one corresponding to thermodynamic equilibrium. But such supersaturation is likely to exist, as shown by theoretical calculation by Djafari [7] who gave a concentration of 0.1 .

This numerical evaluation means that the high density of dislocations observed in the layers 
can be formed directly from the nucleus associated to vacancy clusters. Multiplication of dislocations by conventional sources is not necessary to form the microstructure (Fig. 6).

The final target is to make $\mathrm{CdTe}$ or $(\mathrm{CdHg}) \mathrm{Te}$ layer. The $\mathrm{ZnTe}$ layer is an intermediate which is grown to spread the misfit (Tab. I) over some distance, that is to distribute the internal stresses in a controlled manner: We expect that the dislocations created in ZnTe (Fig. 5) are used at the interface with CdTe to accommodate the $6 \%$ misfit (Tab. I). Indeed the dislocation density falls from $2 \times 10^{11} \mathrm{~cm}^{-2}$ (Fig. 5) to $5 \times 10^{9} \mathrm{~cm}^{-2}$ in a $0.5 \mu \mathrm{m}$ thick CdTe layer (Fig. 6). The trapping of threading dislocations at interfaces is a common observation in III.V compounds, where superiattices are currently introduced for that purpose $[1,2]$.

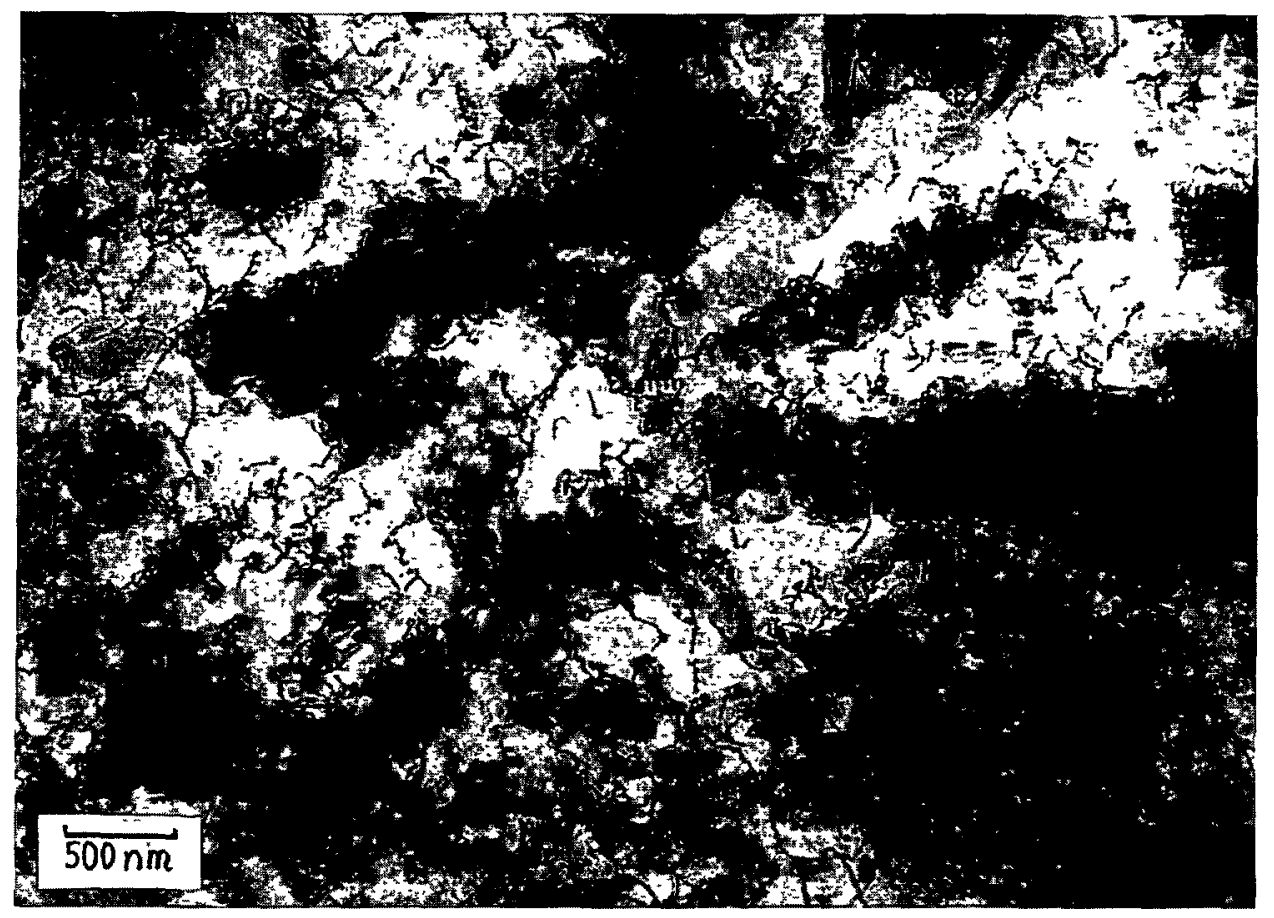

Fig. 6. - Dislocations in a layer of CdTe at a level of $0.5 \mu \mathrm{m}$ above the interface CdTe/ZnTe. The dislocation density is about $5 \times 10^{9} \mathrm{~cm}^{-2}$ Some stacking faults, common in CdTe, are observed.

In spite of the low mismatch between CdTe and $\mathrm{HgTe}$ (Tab. I), dislocations can be bent at the interface between the two layers (Fig. 7). The ( $\mathrm{CdHg}) \mathrm{Te}$ layer is the result of the interdiffusion of $\mathrm{CdTe} / \mathrm{HgTe}$ multi-layers, which create good internal stress conditions for dislocation annihilation. The densities at the surface are of the order of $10^{4}-10^{5} \mathrm{~cm}^{-2}$ However, other mechanisms for the annihilation of dislocations are operative, since densities lower than the one of figure 6 are observed in thick CdTe layers; if is five times lower at $2 \mu \mathrm{m}$ from the $\mathrm{ZnTe} / \mathrm{CdTe}$ interface than at $0.5 \mathrm{\mu m}$ (Fig. 6). This suggests a recovery mechanism typical of II-VI semiconductors where dislocation mobilities are high at temperatures between $350-400^{\circ} \mathrm{C}$. This behaviour relates to the one observed in III-V semiconductors after additional annealing $[1,2]$. 


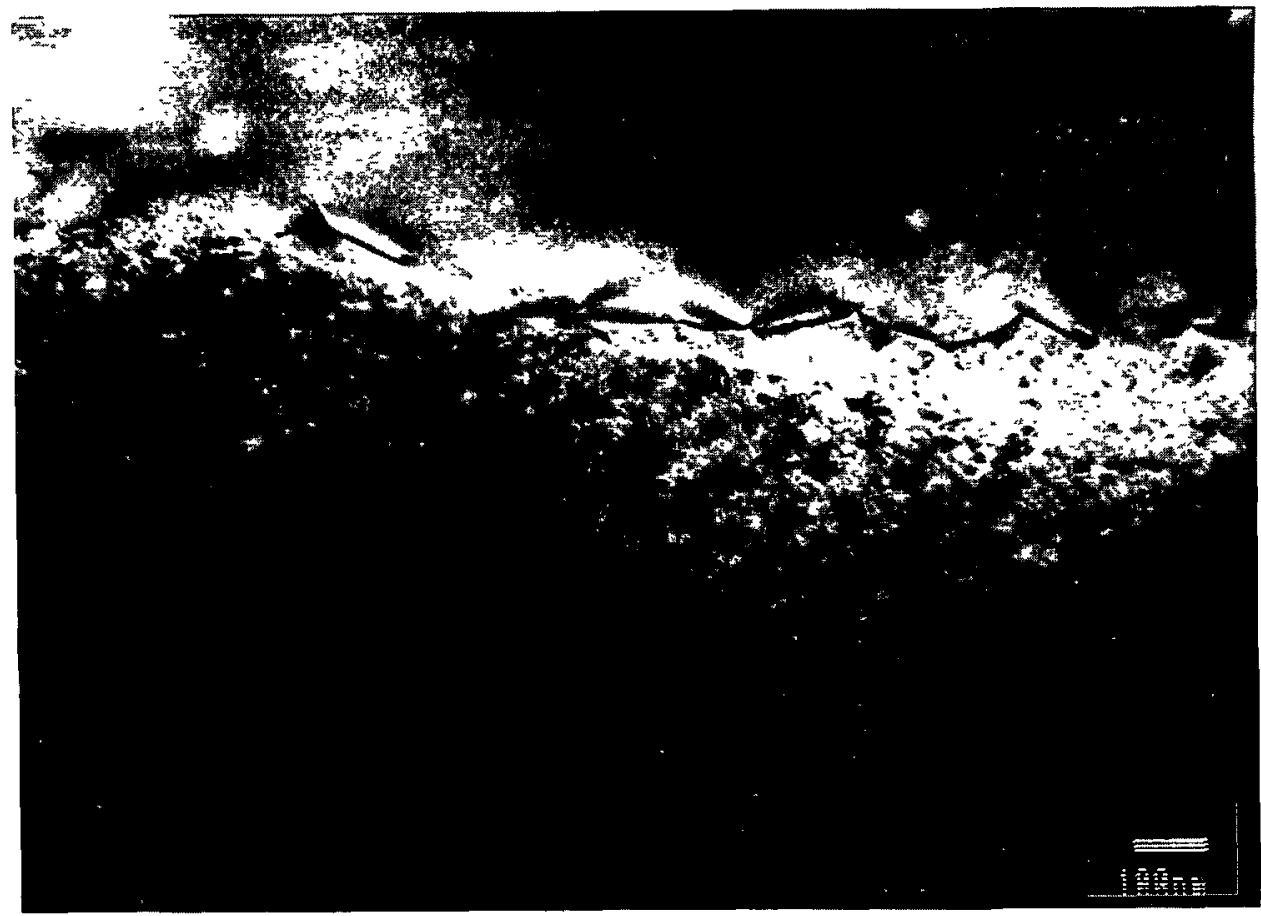

Fig. 7. - Cross section micrograph; bending of a dislocation at the interface between $\mathrm{CdTe}$ and (HgCd)Te.

\section{Conclusions and summary.}

We have focused our attention in this paper on one class of defects in CdTe/ZnTe grown on GaAs by OMCVD, i.e. dislocations which are present in high densities. Other types of defects will be described in further publications $[11,15]$.

We have suggested that the origin of dislocations can be associated with point defect clusters which are very likely to be abundant in view of the non-equilibrium growth conditions. The high mobility of dislocations allow these loops to expand as soon as the critical thickness is reached. These features are typical of II-VI semiconductors. The recovery processes are particularly efficient in these compounds where diffusivity is high [11].

\section{Acknowledgments.}

This work received partial financial support from the DRET-DRED-PIRMAT/CNRS contract. The authors are grateful to $R$. Druilhe and $R$. Triboulet who performed the OMCVD preparations of the specimens. 


\section{References}

[1] Fang S. F., Adomi K., Lyer S., Markoç H., Zabel H., Chol C. and Otsuka N., J. Appl. Phys. 68 (1990) R-31.

[2] Houdré R. and Markoç H., C. Rev. Solid State 16 (1990).

[3] Triboulet R., Semicond. Sci. Technol. 5 (1990) 1073.

[4] Feldman R. D., J. Vac. Sci. Technol. A 8 (May/June 1990) 1888.

[5] Desjonquères F., Tromson-Carli A., Cheuvart P., Druilhe R., Grattepain C., Katty A., Marfaing Y., Triboulet R. and LoRans D., J. Cryst. Growth 107 (1991) 626.

[6] Orlova A. and Sieber B., Acta Metal. 32 (1984) 1045.

[7] Diafari Rouhani M., Laroussi M., Amrani A. and Esteve D., J. Cryst. Growth 101-1 (1990) 122.

[8] Philibert J., Dislocations et déformation plastique (Editıons de Physique, 1979) p. 114.

[9] Ball C. A. B. and VAn Der Merve J. H., Dislocations in solid, vol. 6 (F.R.N. Nabarro Editor, 1983) p. 121.

[10] Cibert J., André R., Deshayes C., Feulllet G., Jouneau P. H., Le Sidang, Mallard R., Nahmani A., Siminadakar K. and Tatarenko S., Superlattices and Microstructures 9 (1991) 271.

[11] Patriarche G., Triboulet R., Marfaing Y, and Castaing J., To be published in $J$. Crystal Growth.

[12] Hartmann H., Mach R. and Selle B., Wide gap II-VI compounds as electronic materials. Current topics in Material Science, vol. 9 (E. Kaldis Editor, 1982).

[13] Fontaine C., Thèse de Doctorat de l'Université Scientifique et Médicale de Grenoble (1986).

[14] Jimenez-Melendo M., Djemel A., Rivière J. P., Castaing J. and Thomas C., Rev Phys. Appl. 23 (1988) 251.

[15] Patriarche G., Tromson Carl. A., Rivière J. P., Triboulet R., Marfaing Y. and CasTAING J., To be published in Phvs. Status Solidl. 